\section{WAR INJURIES OF THE CHEST 3rd Edition}

By H. Morriston Davies and Robert CoOpe. E. \& S. Livingstone. I942. 6s.

As the authors state in their preface, this is a book designed to fill the gaps in the literature of chest injuries between short articles published in various journals and much larger monographs. It certainly does this extremely well. The book is readable, and deals with the subject very much from the practical point of view. There are 36 Figures, all of them quite descriptive in themselves, and a study of these alone helps quite considerably in the understanding of the many physiological problems involved in chest injuries.

There is, however, one phvsiological condition which has been inadequately described. Under the heading "Anoxia and Cyanosis" the statement that "this leads to the production of anoxia with its associated cyanosis" is made. This implies that anoxia and cyanosis are one and the same thing, yet nothing can be further from the truth. It is well known that many a patient may be suffering from a severe anoxia and yet not show any sign of cyanosis. Similarly, a very plethoric patient may be cyanosed without being anoxic to any degree. Further on it is stated that "unless measures are taken to overcome this anoxia in its early stages, the cyanosis will soon reach a dangerous livid stage." The sooner this teaching is dispelled the better will be the patient's chance of recovery. Anoxia without cyanosis may be much more fatal to the patient because its effects may have few outward signs.

Treatment of the various conditions described in the book is well outlined, and the book is packed with small but essential practical details, all of which, once known, make one's treatment so much easier. However, in view of the fact that sulphonilamides are not active in the presence of pus, it is perhaps questionable to fill an infected pleural space with sulphonilamide powder.

But one cannot get away from the fact that this book is compact, practical and readable, and does fill most satisfactorily the gaps in the literature of chest injuries. It should be widely perused.

\section{WAR WOUNDS AND IN.JURIES}

Edited by Rodney Maingot; E. G. Slesinger and ERnest Fletcher. Second Edition. Edward Arnold, London. 1943. Price 35s.

In the solid and wholehearted competition among the various sections of the country to help win the war, surgeons can read with pride, satisfaction and profit War Wounds and Injuries, edited by Maingot, Slesinger and Fletcher, and published by Edward Arnold and Co., as a fine contribution to the war effort in their own particular sphere of endeavour. This book, with a foreword by Lord Horder, has now entered its second edition, and acting on his original recommendation has included chapters on burns and sepsis. Surgery, like all evolutionary phenomena, heads slowly towards greater complexity, but in war time it grows in fits and starts in particular directions. This impetus of war is most clearly seen in these pages, where there is almost a riotous outbreak of weighing, sifting and testing new ideas, new methods and new techniques-a royal display of surgical ingenuity in many direc- tions. Such a setting therefore is a spur to surgical incentive and the Editors have invited men of standing in the profession to write, unfettered, upon their own subjects in so far as they concern war wounds. Such a work must naturally be regarded as a book of reference, and in contrast to the older established text-books to which we are more accustomed, provides in variety what it lacks in uniformity. Consequently the reader is carried through some twenty-two chapters at a walk, an amble, a trot or a canter, according to the literary style or material of the different contributors. But one thing is clear; in a work of this kind, where the subjects dovetail into one or more specialities, there is a more converging outlook between the views of the pure specialist and the general surgeon. To attain cohesion this must be so, for it is one thing to offer the counsel of perfection from centres specially fitted out for the treatment of special cases, and another for the untrained man in the foreward battle area to understand the necessary first principles and carry them out. There has been therefore a most commendable tendency by those writing on behalf of pure specialities to leaven their material to the requirements of the standard loaf.

It must be recognised that nearly all the contributors are civilian surgeons who went through the surgical mill of the last war. They may therefore be said to be steeped in the principles of war surgery, but on the other hand much has happened in surgery since the last war, and the methods of waging modern warfare are quite dissimilar. For this reason it is a fair criticism to ask how far this counsel of perfection fits in with the requirements at the battle front, and whether sufficient time has not now elapsed for the inclusion of chapters by men who have been actively engaged in the handling of the wounded. It is true that some of this infor-. mation has been acquired from men back from the various fronts, and a good deal of knowledge has been disseminated through those successful conferences of "The Interallied Committee of War Medicine" so wisely sponsored by the Royal Society of Medicine. It is obvious for security reasons that much of this knowledge should not be released for print, but it is also obvious that much of this information, unless active steps are taken to preserve it by the Service chiefs, will "waste its sweetness in the desert air."

There has been a great revolution in the treatment of war wounds since the last war. The present war has piled on problems which have had to be met by opportunism and improvisation. Consequently we are passing through a stage of transition, and it is probable that many of our present fads will lose their popularity. For instance it is difficult for the teaching surgeon reading some of these chapters, such as that on burns, to know which are the most suitable methods he should impress upon his students, for we seem far from agreement or finality on the subject. Then again there is the question of sulphonamide treatment. Practically every contributor subscribes to its oral and local use. Only one writer decries its local use, in that its wholesale recommendation has done more harm than good, and led to deficient surgical treatment. This is a tiny word of caution, because it has become so much "the rage" that in the mind of the average medical student it is rapidly becoming a sort of short cut to surgery. To the hospital house officer it is almost a panacea. But in spite of this, its abuse, and the limitations of its 